\title{
Optical sensors monitor flames
}

Javier Ballester, Ana Sanz, Ricardo Hernández, and Andrzej Smolarz

Optical sensors and signal processing algorithms can analyze the radiation emitted by flames to monitor and control industrial burners.

The permanent optimization of combustion equipment could provide efficiency, reliability, and reduced-pollution benefits. However, current capabilities for monitoring and control of industrial flames are limited; the lack of reliable diagnostic techniques is a major obstacle. The information provided by conventional combustion instruments is clearly insufficient to act on the burner settings, which would be an effective way to optimize the flame (and, for example, reduce emissions of carbon monoxide and/or nitrogen oxides). Novel instrumentation capable of obtaining direct information from the flame is needed to develop reliable monitoring methods before we can implement advanced combustion controls. ${ }^{1,2}$

Optical sensors could help greatly to fill this gap. Laser-based techniques are an invaluable tool for the investigation of flames or flows, but they are still restricted to research. However, passive sensors offer potential for characterizing a flame's properties from the rich information contained in the flame's spontaneouslyemitted radiation. Optical sensors offer the advantages of being selective, fast, and able to gather data even in extremely hostile environments. There are many ways in which they can be used to obtain useful information from combustion systems.

Radiation at some specific wavelengths, associated to the emission of some chemical species, can be used to obtain quantitative results. For example, the emission bands in the range 1$4 \mu \mathrm{m}$ for $\mathrm{HO}_{2}$ and $\mathrm{CO}_{2}$ can be monitored to measure gas composition and temperature. ${ }^{3}$ Several groups are working on this approach, which is in pre-commercial development.

The most common strategy, however, is to use the radiation signal as a signature of the flame that can be related to some properties or to situations previously characterized. ${ }^{4-6}$ Our group at the Laboratory for Research on Combustion Technologies (LITEC) in Zaragoza, Spain, is investigating different methods along this line..$^{7-9}$

One possibility is to analyze the average level of radiation and its fluctuations. LITEC has been working with a Si photodiode (sensitive from 190-1100nm) and with a photomultiplier

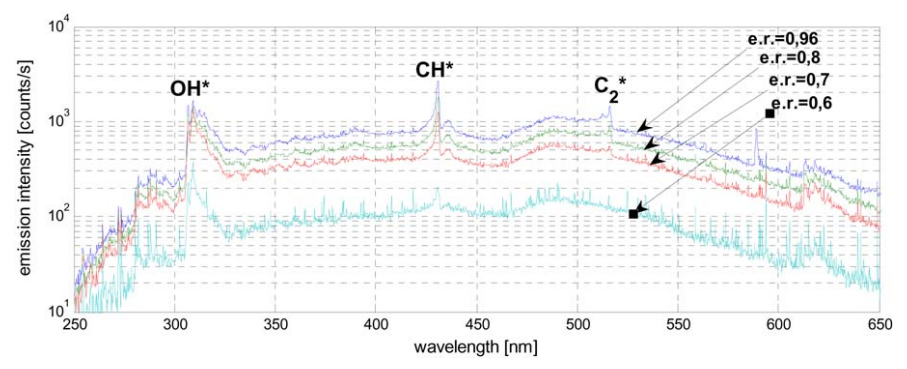

Figure 1. Emission spectra for premixed flames with different equivalence ratios (e.r.), which describe the fuel-air ratios.

tube with a filter at $310 \pm 10 \mathrm{~nm}$. The first sensor provides a measure of the luminosity of the flame, while the signal obtained by the second sensor is associated with the quantity of excited $\mathrm{OH}$ radicals. A strong relationship has been obtained between the average and standard deviation of the radiation signals and the characteristics of the flames in a model of an industrial burner. For example, good estimations of nitrogen oxide $\left(\mathrm{NO}_{x}\right)$ emissions have been obtained using the radiation signals as the only input to neural-network models.

Flame-emitted radiation, in general, fluctuates greatly and the frequency content of the fluctuations contains relevant information. The power-spectral-density function of the radiation shows some discrete peaks superimposed over a continuous spectrum. The location and strength of the peaks-as well as the variation of the continuous level with frequency-are modified when burner settings change. These parameters can be related, for example, to the acoustic properties of the combustion chamber. But the spectrum can be also treated as a signature of the flame. This can be used, for example, to identify it with respect to known situations. Remarkably high success rates have been obtained when estimating actual burner settings or $\mathrm{NO}_{x}$ emissions solely from the frequency spectra of the radiation around 310nm.

A different approach is based on the analysis of spectrallyresolved radiation signals. ${ }^{10,11}$ Figure 1 shows the radiation spectra obtained from premixed flames with different equivalence ratios (ERs). The ER is a measure of the fuel-to-air ratio, and is a key parameter in lean premixed combustors, which are in- 
creasingly used in gas turbines and other industrial applications. There is a narrow optimal range for ER: too-high values lead to increased $\mathrm{NO}_{x}$ emissions while too-low ones can result in high carbon-monoxide emissions, pulsations, or flame blow-off. Hence, developing instrumentation to measure ER is an important objective in this area. Several groups have demonstrated that radiation spectra like those shown can be analyzed to obtain reliable estimates of ER. LITEC is working on this approach. We are also applying this method to different fuel compositions, such as those that can appear in biomass gasification or for $\mathrm{H}_{2}$ enriched gases, which also affect the radiation spectra.

Optical sensors are a promising method for monitoring and controlling a wide range of combustion applications. LITEC is developing data-interpretation strategies oriented to different cases, such as large pulverised coal burners or lean-premixed combustion of gaseous fuels.

\section{Author Information}

\section{Javier Ballester}

Fluid Mechanics Group

University of Zaragoza

Laboratory for Research on Combustion Technologies (LITEC)

Joint Center CSIC-DGA-Univ. Zaragoza

Zaragoza, Spain

http:/ / www.unizar.es/lci

Dr. Javier Ballester belongs to the Fluids Mechanics Group at the Centro Politecnico Superior (University of Zaragoza) and is the head of the Industrial Combustion Laboratory of LITEC. He has been involved, in most cases as principal investigator, in many projects related to applied fluid mechanics and combustion, some of them oriented to the advanced monitoring and control of industrial flames.

\section{Ana Sanz}

\section{and Ricardo Hernández}

Laboratory for Research on Combustion Technologies (LITEC)

Joint Center CSIC-DGA-Univ. Zaragoza

Zaragoza, Spain

http:/ / www.pollub.pl

http:/ /www.unizar.es/lci

Ana Sanz is a graduate student at LITEC, where she has been working in combustion research since 2001. She earned her Industrial Engineering degree from the University of Zaragoza. As a part of her Ph.D. work, she is developing advanced systems of optimization and control for different processes from combustion.
LCI workgroup. In 2005 he obtained an FPU scholarship for his doctoral studies. At present he is working on combustion instabilities in lean premixed gas turbines.

\section{Andrzej Smolarz}

Dept. of Electronics

Lublin University of Technology

Lublin, Poland

Laboratory for Research on Combustion Technologies (LITEC) Joint Center CSIC-DGA-Univ. Zaragoza

Zaragoza, Spain

http:/ /www.pollub.pl

http://www.unizar.es/lci

Andrzej Smolarz was a member of organizing committee of last three Technology and Application of Lightguides conferences in Poland, co-editor of the proceedings volumes, and has authored many papers on optical flame sensing.

\section{References}

1. N. Docquier and S. Candel, Combustion control and sensors: a review, Prog. Energy Combust. Sci. 28, pp. 107-150, 2002

2. J. B. Michel, C. Champinot, and J. Dugue, State of the art on emerging combustion control sensors, 6 th Int'l Conf. on Tech. and Combustion for a Clean Environment, Porto, 2001.

3. M. E. Weber, J. Wang, S. T. Sanders, D. S. Baer, and R. K. Hanson, In-situ combustion measurements of $\mathrm{CO}, \mathrm{CO}_{2}, \mathrm{H}_{2} \mathrm{O}$ and temperature using diode laser absorption sensors, Proc. Combust. Inst. 28, pp. 407-413, 2000.

4. M. Khesin, Demonstration of new frequency-based flame monitoring system, Proc. 59th Ann. Mtg. of the American Power Conf. 58-II, pp. 1010-1013, Chicago, April 1997.

5. L. Xu, Y. Yan, S. Cornwell, and G. Riley, On-line fuel identification using digital signal processing and fuzzy inference techniques, IEEE Trans. Instrum. Meas. 53, pp. 1316-1320, 2004.

6. J. B. Michel, O. Chételat, N. Weber, and O. Sari, Flame signature as a low-cost flame control method, 5th Int'1 Conf. on Tech. and Combustion for a Clean Environment pp. 1251-1253, Lisbon, 1999.

7. J. Ballester, A. Sanz, R. Hernández, and A. Smolarz, Detection and analysis of emitted radiation for advanced monitoring and control of combustors, Proc. SPIE 5948, 2005. 8. J. Ballester, A. Sanz, R. Hernández, A. Smolarz, J. Barroso, M. González, and A. Pina, Identification of combustion conditions using flame sensors, AFRC Symposium-Dynamics and Control of Industrial Combustion Processes, Atlanta GA, Nov. 2005.

9. A. Sanz, J. Ballester, and R. Hernández, Advanced monitoring and control of burners using flame sensors, 7th Euro. Conf. on Industrial Furnaces and Boilers, Porto, April 2006.

10. N. Doquier, F. Lacas, and S. Candel, Closed-loop equivalence ratio control of premixed combustors using spectrally resolved chemiluminescence measurements, Proc. Combust. Inst. 29, pp. 139-145, 2002.

11. T. M. Muruganandam, B. Kim, R. Olsen, M. Patel, B. Romig, and J. M. Seitzman, Chemiluminescence based sensors for turbine engines 39th AIAA/ASME/SAE/ASEE Joint Propulsion Conf. and Exhibit, AIAA 2003-4490, pp. 20-23, Huntsville, AL, USA, July 2003. 